International Journal of Managing Value and Supply Chains (IJMVSC) Vol.4, No. 2, June 2013

\title{
Study on Validation of Wholesaler Selection of Personal Protective Equipment to Improve Safety Performance in a Construction Organization in India
}

\author{
SVS Raja Prasad ${ }^{1}$ and Dr. YVSSSV Prasada Rao ${ }^{2}$ \\ ${ }^{1}$ Research Scholar, Koneru Lakshmaiah Education Foundation (K L University), \\ Vaddeswaram, India \& Associate Professor, NICMAR, Hyderabad, AP, India. \\ sunkuvsrpeyahoo.co.in \\ ${ }^{2}$ Dean, Koneru Lakshmaiah Education Foundation (KL University) Vaddeswaram, \\ AP, India \\ prasadarao_yvsssveyahoo.co.in
}

\begin{abstract}
Most of the construction organizations in India rely on personal protective equipment (PPE) to reduce lavoid accidents at workplace instead of adopting engineering and administrative controls, and selecting a wholesaler is an important decision making process, as quality of PPE is of paramount importance in avoiding accidents. The wholesaler selection is crucial particularly for construction organizations involved in execution of works in remote areas like construction of thermal electric plants, highways, buildings etc. It is difficult to find wholesalers in the vicinity of workplace. As construction organizations are more dependent on wholesalers, the direct and indirect consequences of poor decision making is more severe, as non standard/poor quality PPE results into injuries and sometimes fatal accidents also occur. In the present study, a wholesaler selection model using Integer linear programming (ILP) for multi product and multi wholesalers has been proposed, and the model is validated in a construction organization in which the process of purchasing is centralized. The construction organization was involved in execution of various construction activities at four different sites in northern region of India.
\end{abstract}

Keywords: Personal Protective Equipment (PPE), Integer Linear Programming (ILP)), Wholesaler (WS), Analytic Hierarchy Process (AHP)

\section{Introduction}

Construction ranks second in terms of contribution to GDP (a share of 8\%) followed by Agriculture in India. Construction Industry has recorded enormous growth worldwide and particularly in last decade. It is crucial for successful construction activity to provide safe and healthy environment to the employees. The concern of safety has to start from the design stage and continues till the facilities are delivered to the owner. Construction industry is hazardous and labour intensive contributing to injuries and accidents .Construction industry is risk prone owing to its being in unorganized sector for all stakeholders. In India, though a well formulated

DOI: $10.5121 /$ ijmvsc. 2013.4202 
legislation on safety has been enacted, it is not being enforced by most of the state Governments. Most of the construction workers are migratory and unskilled. [1]

The hierarchy of accident prevention is through engineering controls, administrative controls and usage of PPE. During planning stage of construction itself engineering controls are to be incorporated. By utilizing a systematic approach to safety, occupational health safety management system optimize the overall co-ordination of prevention and control measures embodied in these three philosophies, and so offer much more than the traditional five treatment options advocated by the hierarchy of controls - elimination, substitution; isolation; administrative controls and lastly personal protective equipment [2].

PPE is the last stage of hierarchy controls and it is to be implemented in case of failure to implement engineering and administrative controls. Reliability and effectiveness of PPE is of paramount importance in ensuring the safety of employees at construction sites. Assessing the requirement, training\& providing to PPE employees and monitoring PPE compliance are the responsibility of the management. The employees must be imparted knowledge on occupational safety and health to deal with hazardous situations that may arise during their course of execution of various construction activities. [3].The provision of PPE can be argued to be the most significant element in terms of costs of accident prevention and prevention of accidents on construction sites. Therefore adequate provision of these equipments can help contribute to prevention of accidents on construction sites. Indian standards are existing for PPE in India which gives information relating specifications, testing, inspection, training of PPE but non standard PPE are also available which are not meeting the requirements as per Indian standard codes.

Purchase of PPE with relevant test certificates is of paramount importance for any construction organization, which must be preceded by selection of reliable wholesalers for supplying PPE. Several wholesaler selection methods are available but owing to modeling flexibility provided by integer linear programming (ILP), this method was adopted in the present study. A function can be maximized or minimized by using integer linear programming and it operates with 0 -1[4].The allocation of PPE to wholesalers is determined by decision variables. The selection of wholesaler for purchase of PPE in a construction organization was studied by using ILP. The purpose of the study is to find a most conducive environment between organization and wholesaler.

\section{Literature Survey}

Personal Protective Equipment (PPE) enhances the safety of an employee. Past studies indicate wearing of suitable PPE reduces accidents. [5].Unsafe acts/conditions coupled with use of improper PPE contributing to high rate of accidents in construction industry. [6] Continuous monitoring of PPE compliance and framing comprehensive purchase policy are the responsibility of safety department. [7]. The safety performance can be improved by providing quality PPE.[8,9,10].Accidents can be avoided or minimized by scouring for reliable supplier of PPE which is not being adhered by construction organizations in India.

To bring in more efficacy in the functioning of purchasing department, it needs to work with several suppliers. It is exceedingly important to address factor of cost as selection criteria. [11]. The supplier selection includes quality, delivery, performance history, warranties, price, technical capability and financial position are few among 23 different listed requirements to gauge supplier efficiency [12]. 
Supplier selection is marred with twin problems viz. single supplier's ability of satisfying the buyer's needs (single sourcing) and secondly no supplier can satisfy buyer's needs (multi sourcing). Thus to overcome these multi criteria problem that includes tangible and intangible criteria; often management decides to split the quantities to be ordered which will foster the competitive environment.[13]

To address tangible and intangible criteria, AHP may be an alternative. This will enable the users to visualize the problem systematically while taking the criteria and sub-criteria in to consideration. This will entail the user to compare and determine the priorities of the criteria and alternatives effectively. The combination of AHP and LP may be considered to take tangible as well as intangible criteria and to optimize order allocation among suppliers.[11].In the present study, AHP along with integer linear programming models were adopted for selection of wholesalers due to more flexibility.

\section{Problem Definition}

Wholesaler selection problem with number of wholesalers and number of PPEs is required to be studied in a construction organization. There are four construction sites under the control of regional office in the northern region of India. The construction activities are highways, power plants and high buildings and all the four sites are located within a radius of $100 \mathrm{kms}$ from regional office. The organization has comprehensive safety policy and the management is committed to extend all facilities to employees as far as safety is concerned. The organization has five regional offices located in the close proximity of sites and the safety wing of the regional office has to monitor the safety performance of the construction under their jurisdiction. One of the prerequisite to improve safety performance is to supply quality PPE's to employees besides reinforcing engineering and administrative controls. The purchase of PPE was centralized and the regional office is vested with powers to purchase and supply quality PPE to construction sites. The safety wing of the regional office deals with purchase of PPE to construction sites as per requirement. Upon receiving requirement of PPE from sites, the safety wing of the regional office process the purchasing activity which involves identifying wholesalers, calling quotations, scrutiny of quotations and placing purchase order. The entire process is time consuming and sometimes the stock of PPE is nil in construction sites and most of the times, the safety wing of the regional office issues instructions to site safety managers to purchase PPE locally. The safety officers of the constructions sites are forced to purchase PPE in local market which are not as per Indian standards, resulting into injuries to employees, increase in cost due to poor quality, client's remarks of the quality and instances of stoppage of work due lack of PPE. To overcome the present situation, the organization needs to select a set of wholesalers for a set of products to supply PPE as per Indian standards with test certificate. The regional office has identified three wholesalers who can supply PPE's to regional office as per Indian standards and the PPE's will be dispatched to construction sites basing on the requirement, from regional office. The PPE's required are safety helmet, Eye protectors, face shields, leather \& cotton hand gloves, rubber hand gloves, leather safety shoes, gum boots, safety harness, ear protectors and air purifying type respirators and is shown in Table 1.The study is to identify a wholesaler who can supply set of PPE among the required and to entrust to supply the set of PPE to regional office. If the number of wholesalers increases, then ordering cost will be high and serviceability may be affected, if the number is low. The organization prefers to restrict the number of wholesalers to three. 
International Journal of Managing Value and Supply Chains (IJMVSC) Vol.4, No. 2, June 2013

Table 1. Required Personal protective equipment

\begin{tabular}{|c|l|l|l|}
\hline PPE No & \multicolumn{1}{|c|}{ IS code } & \multicolumn{1}{c|}{ Name of the PPE } & \multicolumn{1}{c|}{ Purpose } \\
\hline 1 & IS 2925 & Safety helmet & Head protection \\
\hline 2 & IS 5983 & Eye protectors & Eye protection \\
\hline 3 & IS 8521 & Face shields & Eye protection during welding \\
\hline 4 & IS 6994 & $\begin{array}{l}\text { Leather\&cotton hand } \\
\text { gloves }\end{array}$ & $\begin{array}{l}\text { Hand protection during } \\
\text { welding/material handling }\end{array}$ \\
\hline 5 & IS 4770 & Rubber hand gloves & Protection against electric shock \\
\hline 6 & IS 1989 & Leather safety shoe & Leg protection \\
\hline 7 & IS 12254 & Gum boots & Leg protection during concreting \\
\hline 8 & IS 3521 & Safety harness & While working at heights \\
\hline 9 & IS 9167 & Ear protectors & Hearing protection. \\
\hline 10 & IS 9473 & Respiratory protection & Protection against dust/particles \\
\hline
\end{tabular}

Figure 1 shows the relationship among wholesaler, regional office and construction sites.

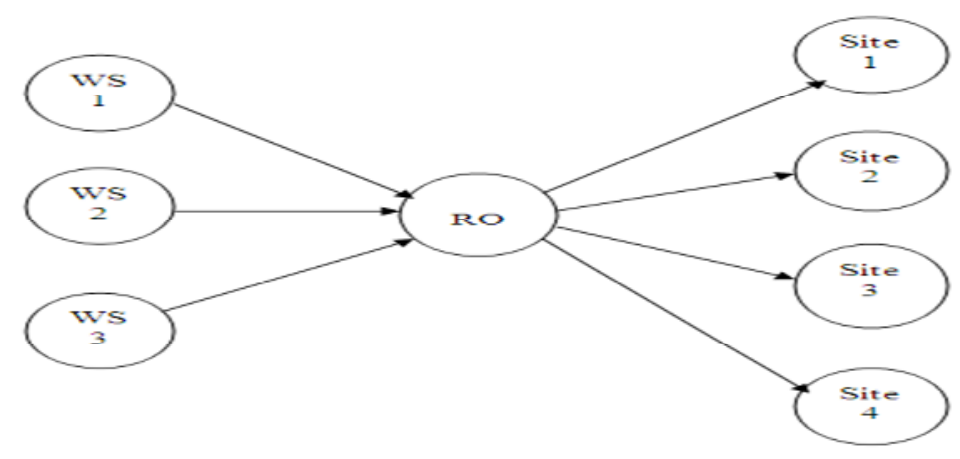

Figure1. Two stage supply chain

\section{Methodology}

\subsection{Integer Linear Programming}

A zero one ILP is a special case integer programming model in which all decision variables are binary numbers. ILP is useful in making decisions such as accept or reject and yes or no type answers. [14].All decision variables are restricted to take only binary values. The decision variables in ILP should be integers.

Wholesaler selection problem is formulated using general assignment problem. The general assignment Problem [15] can be superimposed onto the current wholesaler assignment problem. The preference of each wholesaler of all the products is found out by Analytical hierarchy process. The mathematical model developed here to illustrate the objective functions involving the allocation of product to multiple wholesalers and vice versa, there's a scope for maximizing the preference weightage while carrying out this assignment. The required number of wholesalers for each item depends upon the requirement of the buying organization. This is considered as the first constraint. By considering the past performance of the wholesaler, the maximum number of 
products that can be allotted to each wholesaler is considered as the second constraint. The total number of wholesaler assignments required for a set of PPE is considered as the third constraint.

The formulated ILP model is presented hereunder.

Decision variable: $=\left\{\begin{array}{l}1, \text { wholesaler is allocated to PPE } \mathrm{j} \\ 0, \text { otherwise }\end{array}\right.$

Where,

$\mathrm{I}=$ wholesaler index $, \mathrm{i}=1,2 \ldots \mathrm{K}, \mathrm{K}=$ Total number of wholesalers in a set

$\mathrm{J}=$ PPE index $\quad \mathrm{j}=1,2 \ldots \mathrm{L}, \mathrm{L}=$ Number of PPE in a set

$\mathrm{W}_{\mathrm{ij}}=$ Preference weightage of wholesaler 'I' for the PPE ' $\mathrm{j}$ '

$\mathrm{M}=$ Minimum requirement of wholesalers for product ' $\mathrm{j}$ '

$\mathrm{N}=$ Maximum number PPE's allocated to wholesaler 'I'

$S=$ Total number of wholesaler assignments needed for ' $L$ ' number of PPE's

$\operatorname{Maximize} \mathrm{Z}=\sum_{\mathrm{i}=1}^{\mathrm{K}} \sum_{\mathrm{j}=1}^{\mathrm{L}} \mathrm{W}_{\mathrm{ij}} \mathrm{P}_{\mathrm{ij}}$

T he objective function represents the maximization of the preference weightage subject to,

$\mathrm{K}$

$\sum_{\mathrm{I}=1} \mathrm{P}_{\mathrm{ij}} \geq \mathrm{M}_{\mathrm{j}}$

This constraint ensures minimum requirement of the number of wholesalers for each PPE.

$$
\sum_{\mathrm{j}=1}^{\mathrm{L}} \mathrm{P}_{\mathrm{ij}} \leq \mathrm{N}_{\mathrm{i}}
$$

The equation (3) indemnifies allocation of maximum number of PPE's to wholesaler.

$$
\sum_{\mathrm{i}=1}^{\mathrm{K}} \sum_{\mathrm{j}=1}^{\mathrm{L}} \mathrm{Pij} \leq \mathrm{S}
$$

This equation (4) indemnifies the total wholesaler assignments does not exceed the availability.

$$
\mathrm{P}_{\mathrm{ij}}=1 \text { or } 0
$$

The equation (5) ensures non negative restrictions.

\subsection{Analytic Hierarchy Process}

The Analytic Hierarchy Process (AHP) is measurement processes based on the expert's evaluation to obtain priorities through pair wise comparisons. The priorities cannot be measured in relative terms. The importance of one element over the other for a specific attribute relies on expert's evaluation. The drawback of the AHP is due to expert's evaluation may be inconsistent sometimes, resulting into inconsistency. [16].AHP is a multi-level hierarchical structure of characteristics, criteria and decision alternatives.

A group of five evaluators were interviewed by framing a questionnaire comprising of price, quality, delivery reliability, availability of PPE, replacement policy, issue of test certificate, previous complaints; for preference of each wholesaler of all the PPE's. There is a possibility of 
maximizing preference weightage as a PPE can be allocated to multiple wholesalers and vice versa. The evaluators are safety managers of the four construction sites and regional safety manager and all the experts are having more than ten years of work experience in the field of construction safety. The evaluators were requested to compare preference of wholesaler with PPE's pair wisely with reference to questionnaire using a nine -point scale of intensity, shown in Table 2.[17]

Table 2 .Intensities of Relative Importance for Pair wise Comparison

\begin{tabular}{|l|l|}
\hline \multicolumn{1}{|c|}{ Intensity } & \multicolumn{1}{c|}{ Definition } \\
\hline 1 & Equal importance \\
\hline 3 & Moderate importance of one over another \\
\hline 5 & Essential or strong importance \\
\hline 7 & Demonstrated importance \\
\hline 9 & Extreme importance \\
\hline $2,4,6,8$ & $\begin{array}{l}\text { Intensities values between the two } \\
\text { adjacent judgments }\end{array}$ \\
\hline
\end{tabular}

\section{Results}

The computations and analysis of interview findings were made using computer software, Expert Choice $^{\mathrm{TM}}[18]$. The preference weightages obtained by AHP for wholesalers with all PPE's is shown in Table 3.

Table3: Preference weightages

\begin{tabular}{|l|l|l|l|l|l|l|l|l|l|l|}
\hline $\begin{array}{l}\text { W } \\
\text { S }\end{array}$ & PPE 1 & PPE2 & PPE3 & PPE4 & PPE 5 & PPE 6 & PPE 7 & PPE 8 & PPE 9 & PPE 10 \\
\hline 1 & 0.0045 & 0.0058 & 0.0060 & 0.0905 & 0.4537 & 0.1003 & 0.9999 & 1.4346 & 0.5396 & 1.2121 \\
\hline 2 & 0.0008 & 0.0066 & 0.0359 & 0.0898 & 0.9546 & 0.0569 & 0.7987 & 1.3699 & 1.2632 & 0.8564 \\
\hline 3 & 0.0044 & 0.0046 & 0.0089 & 0.0856 & 0.5412 & 0.1565 & 0.0099 & 0.9991 & 1.7814 & 1.2133 \\
\hline
\end{tabular}

Maximize

$0.0045 \mathrm{P}_{11}+0.0058 \mathrm{P}_{12}+0.0060 \mathrm{P}_{13}+0.0905 \mathrm{P}_{14}+0.4537 \mathrm{P}_{15}+0.1003 \mathrm{P}_{16}+0.9999$

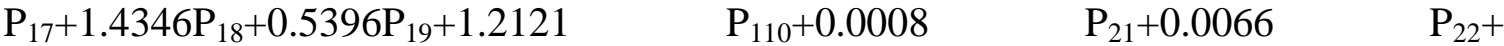

$0.0359 \mathrm{P}_{23}+0.0898 \mathrm{P}_{24}+0.9546 \quad \mathrm{P}_{25}+0.0569 \mathrm{P}_{26}+0.7987 \mathrm{P}_{27}+1.3699 \mathrm{P}_{28}+1.2632 \mathrm{P}_{29}+0.8564$

$\begin{array}{llllllll}\mathrm{P}_{210}+0.00444 & \mathrm{P}_{31}+0.0046 & \mathrm{P}_{32}+0.0089 & \mathrm{P}_{33}+0.0856 & \mathrm{P}_{34}+0.5412 & \mathrm{P}_{35}+0.1565 & \mathrm{P}_{36}+0.0099\end{array}$

$\mathrm{P}_{37}+0.9991 \mathrm{P}_{38}+1.7814 \mathrm{P}_{39}+1.2133 \mathrm{P}_{310}$

Constraint-1 (At least one wholesaler for each PPE)

The safety wing of regional office would like to have at least one wholesaler for each PPE. This is stated as the first constraint.

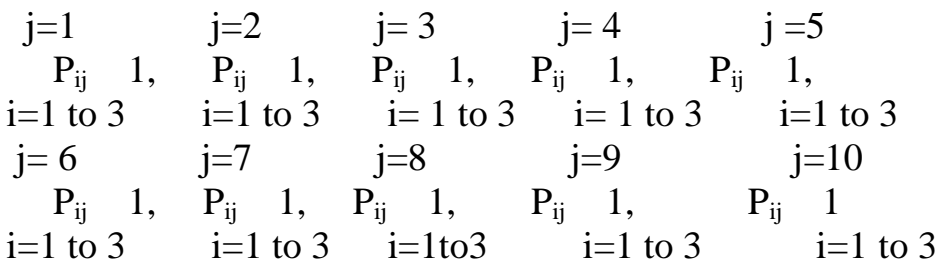


Constraint-2 (Maximum number of PPE allocated to each wholesaler)

This constraint number of PPE's allocated to each wholesaler depends on the sum of preference weightings of that wholesaler.

$$
\begin{aligned}
& \mathrm{j}=1 \text { to } 10 \quad \mathrm{j}=1 \text { to } 10 \quad \mathrm{j}=1 \text { to } 10 \\
& \sum \mathrm{P}_{\mathrm{ij}} \leq 4, \quad \sum \mathrm{P}_{\mathrm{ij}} \leq 3, \quad \sum \mathrm{P}_{\mathrm{ij}} \leq 3, \\
& \mathrm{i}=1 \quad \mathrm{i}=2 \quad \mathrm{i}=3
\end{aligned}
$$

Constraint-3 (Total number of wholesaler assignments for set of all PPE)

The third constraint is formulated that the total number of wholesaler assignments for the set of PPE cannot exceed thirty.

$$
\underset{i=1}{j=1 \text { to } 10}+\underset{\substack{\mathrm{j}=1 \text { to } 10 \\ \mathrm{i}=2}}{\sum \mathrm{P}_{\mathrm{ij}}}+\underset{\substack{\mathrm{j}=1 \\ \mathrm{i}=3}}{\sum \mathrm{P}_{\mathrm{ij}}}=30
$$

\begin{tabular}{|c|c|c|c|c|c|}
\hline $\begin{array}{c}\text { PPE } \\
\text { No }\end{array}$ & IS code & Name of the PPE & Wholesaler1 & Wholesaler2 & Wholesaler3 \\
\hline 1 & IS 2925 & Safety helmet & & & $\checkmark$ \\
\hline 2 & IS 5983 & Eye protectors & $\checkmark$ & & \\
\hline 3 & IS 8521 & Face shields & & $\checkmark$ & \\
\hline 4 & IS 6994 & $\begin{array}{l}\text { Leather and cotton } \\
\text { hand gloves }\end{array}$ & & & $\checkmark$ \\
\hline 5 & IS 4770 & $\begin{array}{l}\text { Rubber hand } \\
\text { gloves }\end{array}$ & & $\checkmark$ & \\
\hline 6 & IS 1989 & Leather safety shoe & & & $\checkmark$ \\
\hline 7 & IS 12254 & Gum boots & $\checkmark$ & & \\
\hline 8 & IS 3521 & Safety harness & $\checkmark$ & & \\
\hline 9 & IS 9167 & Ear protectors & & $\checkmark$ & \\
\hline 10 & IS 9473 & $\begin{array}{l}\text { Respiratory } \\
\text { protection }\end{array}$ & $\checkmark$ & & \\
\hline
\end{tabular}

The problem formulated has been solved using TORA software. The allocated PPE's for each wholesaler obtained from the TORA output are presented in Table 4.

Table 4: Allocation of set of PPE's to set of wholesalers

\section{Conclusions}

Wholesaler selection model using ILP is developed to select the wholesaler for a construction safety environment having two stage supply chain. The model is tested for personal protective equipment supply by the wholesaler and is effectively working out. This model can be effectively implemented not only in construction sector but also in other industries as safety and health is part of the company's policy. Selection of wholesalers to supply PPE is important criteria, as most of the construction organizations in India rely upon last resort of controlling work place hazards that is PPE instead of strengthening engineering and administrative controls. It is also useful for the wholesalers; as a set PPE's are allocated wholesalers facilitates to maintain the inventory of PPE allocated and on the other side construction sites never face a situation of out of stock of PPE from the wholesalers. 
International Journal of Managing Value and Supply Chains (IJMVSC) Vol.4, No. 2, June 2013

\section{References}

1. P.S.Sathish Kumar, M.Logesh Kumar(2012),Viability of Safety and Labor Conditions in Construction Sites, International Journal of Engineering and Innovative Technology,, Vol 2, Iss 6,pp 328-332

2. Winder, C., Makin, A.-M.,(2006). New approaches to OHS risk assessments: expanding traditional models for better managing organizational risks.

3. Mohd Saidin Misnan, Abdul Hakim Mohammed(2007), Proceeding of the Management in Construction Research Conference.

4. A. John Rajan, K. Ganesh and K.V. Narayanan,(2010), Application of Integer Linear Programming Model for Vendor Selection in a Two Stage Supply Chain, Proceedings International Conference on Industrial Engineering \& Operations Management

5 Farooqui, Rizwan U., Ahmed, Syed M. and Azhar, Salman (2007), Safety Management Practices in the Florida Construction Industry.Proceedings of the Associated Schools of construction 43 rd International Conference,

6. Abdelhamid, T. S., and Everett, J. G. (2000), Identifying root causes of construction accidents, Journal of. Construction Engineering, Manage,Vol.,126,Iss 1,pp 52-60.

7. Bruno L. Tanko1 and N.A. Anigbogu (2012)The use of personal protective equipment on construction sites in Nigeria, Proceedings 4th West Africa Built Environment Research Conference,pp 1341-1348

8. Griffin, M. A., \& Neal, A. (2000). Perceptions of Safety at Work: A Framewo Linking Safety Climate to Safety Performance, Knowledge, and Motivation. Journal of Occupational Health Psychology, Vol5, Iss3,pp 347-358.

9. Simard, M., \& Marchand, A. (1994), The behaviour of first-line supervisors in accident prevention and effectiveness in occupational safety. Safety Science, Vol.17,Iss3,pp 169-185.

10. Williams, H., Turner, N., \& Parker, S. K. (2000), The compensatory role of transformational leadership in promoting safety behaviors. Paper presented at the Academy of Management Annual Meeting, Toronto.

11. Ghodsypour SH, O’Brien C(1998), A decision support system for supplier selection using an integrated analytic hierarchy process and linear programming, International Journal of Production Economics, Vol 6,pp, 199-212.

12. Dickson GW. (1966), An analysis of vendor selection systems and decisions. Journal of Purchasing, Vol 2,pp 5- 17

13. Ezgi Aktar Demirtas, Ozden Ustun (2006), An integrated multi objective decision making process for supplier selection and order allocation, The International Journal of Management Science,Vol.36, pp76-90.

14. Taha, Hamdy,(2007).Operations Research: An Introduction ,8th edition. Prentice Hall,

15. Glover, W., Gary A. Kochenberger,(2003) Handbook of Metaheuristics. Kluwer Academic Publishers, pp 570 23. John Rajan A, Suryaprakasa Rao K.\& Ganesh K. (2007), Decision making model for vendor evaluation with respect to product prioritization \&customer expectation, International Journal of Logistics and systems Management, Vol. 3, Iss. 1, pp. 34-55.

16. Thomas L. Saaty,(2008),Decision making with the analytic hierarchy process, International Journal of Services Sciences, Vol. 1, No. 1,pp 83-98.

17. W.K. Law , S. Chan \& K.F. Pun,( 2006), Prioritizing the safety management elements - A Hierarchical analysis for manufacturing enterprises,Industrial Management \& Data Systems, Vol.106 No.6, pp. 778-792

18. Expert Choice,(2002), Expert Choice: Quick Start Guide and Tutorials,ExpertChoice,Inc., 